\title{
TECNOLOGIAS DIGITAIS E RECURSOS EDUCACIONAIS ABERTOS: REFLEXÕES A PARTIR DE UMA FORMAÇÃO DE PROFESSORES DE LÍNGUA INGLESA
}

DOI: $10.48075 /$ RI.V22I2.25098

\author{
Delfina Cristina Paizan ${ }^{1}$ \\ Clodis Boscarioli ${ }^{2}$ \\ João Lucas Cavalheiro Camargo ${ }^{3}$ \\ Etiene Caroline Farias de Mello ${ }^{4}$ \\ Denis Antônio Silva ${ }^{5}$ \\ Mirna Fernanda de Oliveira ${ }^{6}$
}

RESUMO: As novas tecnologias digitais tornaram-se ferramentas úteis para o ensio e a aprendizagem de Língua Estrangeira (LE). Entretanto, o uso pedagogicamente informado dessas tecnologias ainda não é parte da formação dos professores de LE, conforme Hanson-Smith (2016), Mello (2018) e Lins e Boscarioli (2019). Nesse contexto, a UNIOESTE - Foz do Iguaçu ofereceu um curso de $40 \mathrm{~h} / \mathrm{a}$ para professores da rede pública estadual de ensino. De maneira geral, foram tratados os temas Tecnologia e Sociedade, Tecnologia e Educação, Tecnologia e Ensino de LE e Recursos Educacionais Abertos (REA). Tendo em vista os direcionamentos da Base Nacional Comum Curricular (BNCC, 2017), bem como os pressupostos teóricos de Educação Aberta (2013) e Wiley (2014). A partir da pesquisa de cunho qualitativo, buscou-se investigar e promover, de forma reflexiva e crítica, a postura de professor-pesquisador (BORTONI-RICARDO, 2008) para propiciar as atividades, práticas e análises realizadas nesta pesquisa. $O$ retorno dado pelos professores se revelou produtivo ao aproximá-los não somente do uso ético de diferentes tecnologias digitais, com ênfase nos REA, como também das habilidades essenciais de aprendizagem presentes na BNCC. Assim, o objetivo deste trabalho é apresentar a proposta do curso para formação de professores acerca da literacia digital como forma de aliar conhecimento pedagógico a conhecimentos técnicos, cada vez mais relevantes no contexto educacional nacional.

Palavras-Chave: Recursos Educacionais Abertos; Formação Continuada de Professores; Língua Inglesa.

\footnotetext{
1 Professora adjunta na Universidade Estadual do Oeste do Paraná - UNIOESTE/Foz do Iguaçu. Doutora em Educação e Tecnologia pela loE/University of London. E-mail: dpaizan@yahoo.co.uk

2 Professor adjunto na Universidade Estadual do Oeste do Paraná - UNIOESTE/Cascavel. Doutor em Engenharia Elétrica pela Universidade de São Paulo. E-mail: boscarioli@gmail.com

3 Graduado em Letras e Mestre em Ensino pela Universidade Estadual do Oeste do Paraná. E-mail: lucas.camargo_@hotmail.com

4 Professora no SESI - Foz do Iguaçu. Mestre em Ensino pela Universidade Estadual do Oeste do Paraná. E-mail: etimelo@gmail.com

${ }^{5}$ Professor EBTT no Instituto Federal do Paraná - IFPR/Foz do Iguaçu. Mestre em Ensino pela Universidade Estadual do Oeste do Paraná. E-mail: denis.silva@ifpr.edu.br

${ }^{6}$ Professora adjunta na Universidade Estadual do Oeste do Paraná - UNIOESTE/Foz do Iguaçu. Doutora em Linguística e Língua Portuguesa pela Universidade Estadual Paulista Júlio de Mesquita Filho. E-mail: mirna.oliveira@gmail.com
} 


\section{DIGITAL TECHNOLOGIES AND OPEN EDUCATIONAL RESOURCES: REFLECTIONS FROM ENGLISH LANGUAGE TEACHER TRAINING}

ABSTRACT: The new digital technologies have become a useful tool for teaching and learning a foreign language inside the classroom. However, the pedagogically informed usage of those technologies is not yet part of the teachers in training curricula, according to Hanson-Smith (2016), Mello (2018) and Lins and Boscarioli (2019). In this context, UNIOESTE (Western Parana State University) offered a 40 hours course for teachers from public state schools in the region. In general, the course discussed, Technology and Society, Technology and Education, Technology and Language Teaching and Learning, and Open Educational Resources (OER). according to the directions for the National Common Curriculum Basis (BNCC, 2017) from Brazil. From qualitative research, it was sought to investigate and promote, in a reflexive and critical manner, the attitude of a teacher-researcher (BORTONI-RICARDO, 2008) to foster the activities, practices and analyses accomplished in this research. The feedback revealed to be productive for it approached teachers to the ethical usage of technological resources, with an emphasis on OER, as well as the reflection on the basic learning and teaching principles of the BNCC, as well as the theoretical assumptions of Educação Aberta (2013) and Wiley (2014). In this sense, the objective of this paper is to present the proposal for the teacher training course on digital literacy as a means of connecting pedagogical knowledge to technical ones, something increasingly relevant in the national educational context.

Keywords: Open Educational Resources; Continuous Teacher Training; English Language.

\section{INTRODUÇÃO}

As novas tecnologias digitais têm, cada vez mais, se tornado uma ferramenta útil para o ensino e aprendizagem em geral, e se faz imprescindível, para sua inserção nas escolas, em todas as disciplinas e nos diferentes níveis de formação. Tais tecnologias digitais aparecem na Base Nacional Comum Curricular (BNCC, 2017) como competências a serem desenvolvidas, ora pelo uso das linguagens tecnológicas e digitais, ou pelo seu uso de forma significativa, reflexiva e ética. Entretanto, o uso pedagogicamente informado dessas tecnologias não faz, ainda, parte da formação inicial de professores de Língua Estrangeira (LE), como apontado por Hanson-Smith (2016) e reforçado por Lins e Boscarioli (2019) que averiguaram a existência de disciplinas acerca de tecnologias digitais no ensino, em cursos de licenciatura em Letras no estado do Paraná e concluíram que:

O fato de a tecnologia não ser utilizada pelos professores de português e inglês em sua práxis, ou não providenciar aos alunos os benefícios que seriam possíveis, se dá, em parte, devido à aprendizagem incipiente recebida, ou inexistente, na formação inicial em Letras Português/Inglês, visto que metade das universidades analisadas não a abordam em seus documentos, o que é um número expressivo (LINS; BOSCARIOLI; 2019 p. 126).

De fato, a tarefa de inserir o uso de tecnologias e recursos digitais em suas tarefas diárias cabe ao professor, que passa a assumir também o papel de designer de cursos, produtor de objetos de aprendizagem e de tarefas online, o que Ihe exige habilidades de literacia digital. 
Eshet-Alkalai (2004) traz as habilidades necessárias para atuação em ambientes virtuais ou em rede, organizadas em cinco grupos, complementares entre si, quais sejam: habilidade foto-visual (leitura visual, representações); habilidade socioemocional (engajamento nas redes sociais, participação do conhecimento coletivo e compartilhamento de informações); habilidade do pensamento hipermídia (interação com as estruturas constituintes do ambiente online e pensamento não-linear); habilidade informacional (identificação, localização, criação e uso da informação) e habilidade de reprodução (necessidade de reprodução dos elementos virtuais).

Segundo Pinto (2019), o acesso às tecnologias e à rede mundial de computadores (internet) é fundamental na contemporaneidade, bem como o domínio de ferramentas diversas. Entretanto, para além do simples domínio, os usuários necessitam ter habilidades para transitar no universo da cibercultura, de maneira que consigam acessar, analisar, interpretar e avaliar criticamente os conteúdos disponíveis na rede. Além disso, os usuários também precisam produzir seus próprios conteúdos, que não sejam simplesmente cópias ou reproduções de outros usuários. O conjunto de tais habilidades é chamado literacia digital e se constitui em um objetivo a ser alcançado por todos.

Pinto, Cappelli e Boscarioli (2019) trazem uma proposta de formação que contempla habilidades em literacia digital por meio de atividades desenvolvidas em etapas presenciais e a distância, visando aliar conhecimentos técnicos às práticas pedagógicas, considerando questões curriculares. Nesse mesmo sentido, compreendemos que a formação continuada em tecnologias e recursos abertos é um caminho que a universidade possui para alcançar um número relevante de professores da comunidade e fornecer-Ihes espaço para realizarem atividades práticas e reflexões sobre sua prática pedagógica dentro de um novo contexto tecnológico e social.

A tônica do uso de Recursos Educacionais Abertos (REA) é a formação de comunidades solidárias de professores inserindo propostas de atividades em bases de dados que possam ser usados e adaptados, e compartilhados entre seus pares. Dessa forma, pode-se criar uma cultura de partilha de conhecimentos, salutar para a prática pedagógica atenta à evolução da tecnologia e das contribuições e possibilidades que a internet traz para o educador.

Considerando esse contexto, o curso aqui relatado, gratuito, teve por objetivo atender a uma lacuna na formação de professores de Língua Inglesa (LI) de escolas estaduais de Foz do Iguaçu - Paraná, detectada no trabalho de Mello (2018), a qual identificou

o pouco uso das TDIC ${ }^{7}$ nas aulas de inglês, além da falta de formação e, com muito mais significância, é devido à infraestrutura tecnológica precária das escolas, carga horária reduzida e falta de apoio técnico e pedagógico. Embora haja esses entraves, existem esforços por parte de alguns professores para inovar sua práxis por meio das TDIC (MELLO, 2018, p. 5).

Além disso, o conceito de REA também esteve presente na pesquisa: Mello (2018) verificou que o uso deles aliado às tecnologias é uma forma de promover de forma ética a autoria, criatividade e colaboração entre alunos e professores.

Este artigo tem como objetivo apresentar a proposta de uma formação continuada de professores para o uso de tecnologias digitais no ensino de LI, o FORMATEC, bem como relatar as

\footnotetext{
${ }^{7}$ Tecnologias Digitais de Informação e Comunicação.
} 
percepções dos ministrantes e participantes da formação. Para tanto, utilizou-se da revisão bibliográfica para explorar o tema em questão, seguida da análise dos resultados.

Este documento segue assim organizado: A Seção 2 introduz os REA; A Seção 3 descreve a formação continuada ofertada, discutindo seus resultados. Por fim, na Seção 4 são apresentadas as considerações finais e perspectivas do trabalho.

\section{REA - RECURSOS EDUCACIONAIS ABERTOS}

Os REA visam promover o acesso, uso e reuso de bens educacionais, com base na ideia de bens comuns e, segundo Mallmann et al. (2013), possibilitam novas perspectivas de ensino e aprendizagem por meio da colaboração, compartilhamento e recriação de materiais didáticos, contextualizados à realidade da sala de aula. Podem também ser definidos como:

Materiais de ensino, aprendizado e pesquisa, em qualquer suporte ou mídia, que estão sob domínio público, ou estão licenciados de maneira aberta, permitindo que sejam utilizados ou adaptados por terceiros. O uso de formatos técnicos abertos facilita o acesso e reuso potencial dos recursos publicados digitalmente. Recursos educacionais abertos podem incluir cursos completos, partes de cursos, módulos, livros didáticos, artigos de pesquisa, vídeos, testes, software, e qualquer outra ferramenta, material ou técnica que possa apoiar o acesso ao conhecimento (UNESCO, 2011).

De acordo Wiley (2014) os REA têm por características liberdades mínimas que permitem que eles possam ser reusados, revisados, retidos, recombinados e redistribuídos. Essas liberdades mínimas foram, posteriormente, definidas por Gonsales; Sebriam e Markun (2017), às quais ilustramos na Figura 1.

Figura 1 - Características dos REA

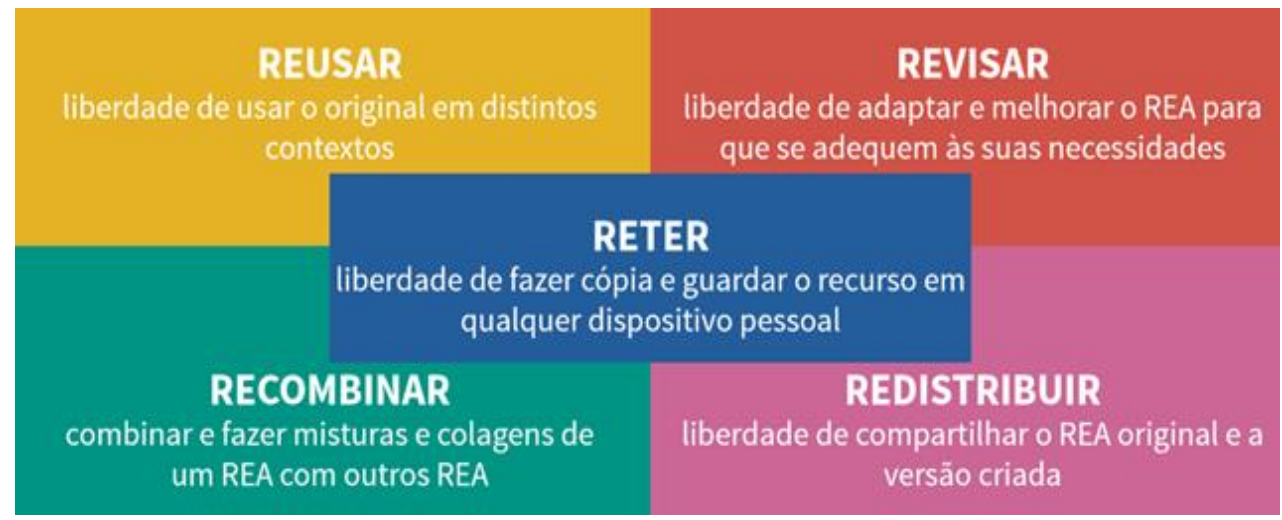

Fonte: Extraída de (Gonsales; Sebrian e Markun 2017, p. 35).

Nesse sentido, os REA podem contribuir no processo de ensino e aprendizagem, pois professor e aluno participam e cooperam para que a aula seja muito mais criativa e produtiva. Mas, para isso, é preciso redefinir a formação do professor e explorar as potencialidades dos REA, a fim de que haja participação, interação e produção colaborativa (MALLMANN et al., 2013).

Para encontrar, produzir e compartilhar os REA, existem repositórios de recursos abertos 
indexados e disponibilizados, como os do Quadro 1. Os repositórios de REA não se limitam aos apresentados nesse quadro, e existem sites e ferramentas de busca que podem auxiliar nesse processo $^{8}$. É notório que a internet é o local onde geralmente os professores vão para encontrar recursos, ideias e formas de dinamizar as aulas. Principalmente se tratando do ensino de língua inglesa (LI), os professores recorrem aos meios tecnológicos para proporcionarem uma maior aproximação e experiência com a LI (MELLO; BOSCARIOLI, 2019).

Quadro 1 - Exemplos de repositórios de REA

\begin{tabular}{|l|l|}
\hline Repositório & Descrição \\
\hline http://portaldoprofessor.mec.gov.br/index & $\begin{array}{l}\text { Portal do Professor. Ambiente virtual de iniciativa do } \\
\text { Ministério da Educação (MEC). }\end{array}$ \\
\hline http://curriculomais.educacao.sp.gov.br/ & $\begin{array}{l}\text { Currículo+. Plataforma online de conteúdos digitais, } \\
\text { articulados com o Currículo do Estado de São Paulo. }\end{array}$ \\
\hline http://www.escolainterativa.diaadia.pr.gov \\
.br/ & $\begin{array}{l}\text { Escola Interativa - Recursos Digitais. Plataforma de } \\
\text { busca que reúne objetos e recursos digitais para } \\
\text { apoiar professores e alunos em processos de ensino } \\
\text { e de aprendizagem. }\end{array}$ \\
\hline http://escoladigital.org.br/ & $\begin{array}{l}\text { Escola Digital. Plataforma de busca que reúne } \\
\text { objetos e recursos digitais voltados a apoiar } \\
\text { processos de ensino e aprendizagem dentro e fora da } \\
\text { sala de aula. }\end{array}$ \\
\hline
\end{tabular}

Fonte: Autores (2020).

É, na maioria das vezes, por meio da internet e das tecnologias que o contato autêntico com cultura e com as variedades linguísticas da LI acontecem. Além disso, o uso de chats, fóruns, vídeos, podcasts, notícias, softwares, dentre tantos outros recursos, também estão presentes nas aulas.

Contudo, para fazer uso desses materiais para elaboração de aulas, é necessário que eles estejam disponíveis para tal e, para modificações e adaptações, que estejam com licença aberta ${ }^{9}$, pois nem tudo que é disponibilizado na internet pode ser utilizado, copiado ou, muito menos, adaptado, se não houver permissão para tal, respeitando-se a autoria. Diante disso, os REA entram como alternativa para a regulamentação do uso de materiais educacionais, visto que seu diferencial é estarem disponibilizados de forma aberta (MELLO; BOSCARIOLI, 2019).

Os REA possibilitariam o uso desses materiais sem a violação da Lei dos Direitos Autorais (LDA), Lei $\mathrm{n}$ - $9.610^{10}$, pois ao utilizar os REA o criador da obra fornece "maior liberdade, para que

\footnotetext{
${ }^{8}$ Para saber como encontrar outros repositórios de REA, acessar o link: http://educacaoaberta.org/cadernorea/encontrar.

${ }^{9}$ Significa que o detentor de direito autoral daquela obra decidiu compartilhar com a sociedade parte de seus direitos patrimoniais de autor, como os direitos de cópia, reprodução, redistribuição, utilização da obra original para criação de obras derivadas, recombinação ou outros (ROSSINI; ABDO, 2011, online).

${ }^{10}$ A Lei garante o direito de o autor fazer o uso de sua obra como desejar e ainda destaca a necessidade de autorização prévia e expressa do autor para a reprodução parcial ou integral. Caso não haja autorização, a LDA prevê punição nas esferas cível e criminal. $\mathrm{O}$ texto da Lei, na íntegra, está disponível em:
} 
terceiros usem, reusem e se apropriem dos recursos" (EDUCAÇÃO ABERTA, 2013, online). Além disso, há uma construção conjunta entre professor e aluno, em que ambos cooperam no processo de ensino e aprendizagem. Nesse modelo o professor pode criar materiais com licença aberta e adaptar conforme contexto e necessidade de cada turma e, depois compartilhar com seus colegas para que estes façam o mesmo.

Foi pensando em incentivar o uso de REA e na lacuna encontrada na pesquisa de Mello (2018) que foi elaborada a formação continuada para professores de LI das escolas públicas de Foz do Iguaçu, o FORMATEC, que a seguir passa a ser relatado como experiência, visando também reprodutibilidade em outros contextos.

\section{O FORMATEC: MÉTODOS, CONTEÚDOS E SUJEITOS}

Esta seção apresenta os aspectos metodológicos da pesquisa e a concepção do curso ofertado, além de discutir as percepções dos ministrantes e participantes, principalmente com ênfase nos REA. Esta investigação fundamenta-se na conceitualização de professor-pesquisador postulada por Bortoni-Ricardo (2008), para pesquisas educacionais envolvendo professores. De cunho qualitativo, busca-se conceber o professor também como pesquisador, logo, imerso nos processos de observação e vivências. Uma vez que todos os pesquisadores desta investigação se envolveram ativamente no processo, considera-se que esse envolveu as interpretações e experiências, que serão utilizadas para descrever os relatos que virão à sequência.

Ademais, adequa-se essa perspectiva não só para os pesquisadores, mas para os participantes envolvidos no curso também. Já que os participantes são professores, as atividades elaboradas para os diferentes módulos buscaram enfatizar o professor a olhar seus arredores com um olhar científico ao buscar estratégias, materiais e ferramentas tecnológicas bem como usar os REA para a produção de seu planejamento, suas atividades, e participação no curso.

Assim, propicia-se a analisar os relatos dos professores enquanto reflexões de suas próprias práticas (BORTONI-RICARDO, 2008), com o propósito de lidarem com as dificuldades enfrentadas no dia-a-dia do professorado, encontrarem caminhos, e sobretudo, usar de forma crítica os conhecimentos apresentados ao longo do curso.

A partir das discussões acima e a partir da identificação de Mello (2018) de lacunas presentes na formação dos professores de LI do Ensino Fundamental II da cidade de Foz do Iguaçu em relação ao uso das novas tecnologias digitais, os integrantes do grupo de pesquisa 'Tecnologia no Uso, no Ensino e na Aprendizagem de Línguas Estrangeiras' da Universidade Estadual do Oeste do Paraná (UNIOESTE), campus de Foz do Iguaçu, desenharam e ofereceram para esses professores, em 2019, um curso de extensão com o objetivo de atender a essa lacuna identificada. As vinte vagas oferecidas em inscrição online via Núcleo Regional de Educação foram rapidamente ocupadas por professores de LI do Ensino Fundamental II e Médio, que trabalhavam em 1, 2 e em até 3 escolas da cidade e região. Dos participantes, 17 eram do sexo feminino e 3 do sexo masculino, todos graduados em Letras Português-Inglês, tendo 4 dos participantes informado terem pós-graduação.

http://www.planalto.gov.br/Ccivil_03/Leis/L9610.htm. 
Entretanto, somente treze professores concluíram o processo formativo.

A carga horária de 40 horas foi dividida em 8 módulos com 33 horas em atividades presenciais ministradas aos sábados, e 7 horas com atividades a distância, incluindo um período para que os professores fizessem uma atividade final de cunho avaliativo reflexivo: um plano de aula com o uso de REA, sua aplicação e posterior socialização à turma em um encontro de encerramento. O conteúdo de cada módulo foi pensado para tratar do uso das tecnologias de uma perspectiva mais ampla até as especificidades do público-alvo.

Para chegar ao conteúdo REA e seu uso em sala de aulas de LI, necessário fez-se abordar outros conteúdos, como pré-requisito de antecessores à essa discussão, de forma incremental de apropriação de conteúdos, para efetivamente formar os professores à luz dos objetivos traçados à formação ofertada. Os módulos estão descritos abaixo:

O Módulo 1 abordou os avanços das tecnologias digitais ao longo dos anos e seus impactos na sociedade, com ênfase no consumo dessas tecnologias e as mudanças comportamentais delas advindas, chegando ao impacto dessas mudanças na escola, nas formas de aprendizagem e na inserção das tecnologias em sala de aula.

O Módulo 2 tratou da inserção de tecnologias na Educação, focando nos aspectos históricos, legais, nas políticas públicas de inserção e de dotação tecnológica no Brasil e no estado do Paraná (SILVA, 2018) e nos impactos que isso traz ao cotidiano escolar e à docência. Além disso, a partir de Filatro e Cavalcanti (2018), foram apresentados os conceitos de Metodologias Inov-ativas e de inovação na Educação e discutidas algumas dessas metodologias que demandam de maneira moderada (metodologias ativas e ágeis) ou intensa (metodologias imersivas e analíticas) o uso de tecnologias.

O Módulo 3 trouxe para os participantes uma perspectiva histórica em relação ao uso dos computadores no ensino de línguas estrangeiras (WARSCHAUER, 1996, THOMAS; REINDERS; WARSCHAUER, 2013, DAVIES; OTTO; RUSCHOFF, 2013, HEALEY, 2016). Também apresentou um panorama das novas tendências em relação dentro desse contexto como a Aprendizagem Híbrida (Blended Learning), a Aprendizagem Móvel (Mobile Learning), a Gamificação e a criação e compartilhamento de informação já fazendo a ligação com o módulo seguinte que trataria de REA.

O Módulo 4 foi sobre REA e tratou de sua conceptualização, onde encontrá-los e como produzi-los, direitos autorais e licenças Creative Commons, discussões e reflexões sobre o uso de materiais prontos da Internet sem a devida verificação da abertura (licença/direitos autorais). Também foram apresentados alguns sites, plataformas e recursos que, juntamente com as tecnologias digitais, os professores poderiam utilizar para criar seus próprios materiais de forma aberta. Por fim, foi feita a produção de um REA, considerando o contexto de sala de aula e compartilhamento na página do curso no Facebook.

O Módulo 5 trouxe aos participantes a Base Nacional Comum Curricular (BNCC, 2017) no que se refere à compreensão e produção oral e escrita: seus Eixos (Oralidade - Leitura - Escrita), Unidades Temáticas, Objetos de Conhecimento e Habilidades. Após reflexão acerca desse tema, o módulo ofereceu a possibilidade de ver a BNCC sendo aplicada no desenho de planos de aula disponíveis na Internet ${ }^{11}$, assim como outras fontes de REA ou ainda, a produção de REA.

\footnotetext{
${ }^{11}$ Disponível em: www.novaescola.org
} 
O Módulo 6 tratou do Eixo Intercultural da BNCC (2017) e trouxe para discussão o conceito de Língua Franca (HOUSE, 2012) e de Cultura (KRAMSCH, 1993). Alguns textos foram lidos e discutidos com os participantes, como Rajagopalan (2003) e Revuz (1998). Esse módulo também contou com a análise de planos de aula em que a BNCC foi usada como ponto de referência. Por fim, o módulo tratou do processo de criação, adaptação ou uso de REA.

O Módulo 7, sobre recursos tecnológicos e o ensino de gramática e vocabulário, teve por objetivo apresentar várias técnicas e exercícios para uso em sala de aula, com ênfase no desafio de planejar aulas utilizando REA, como o caso do sistema de autoria aberto Ensino de Línguas Online $(E L O)^{12}$, trata-se de um sistema aberto, gratuito, que permite que seus usuários trabalhem com objetos licenciados pela Creative Commons, além de permitir que se projetem cursos inteiros a partir de suas propostas de atividades. Utilizando-se dessa ferramenta foi proposta algumas atividades, as quais os participantes realizaram como forma de colocar em prática os conceitos apresentados.

Cabe enfatizarmos que como os participantes ainda não tinham conhecimento do Referencial Curricular do Estado do Paraná que estava, então, em versão preliminar ${ }^{13}$, os módulos referentes ao ensino e aprendizagem de línguas tomou como apoio a Base Nacional Comum Curricular (BNCC, 2017).

\section{OS RESULTADOS EM FOCO}

O projeto de extensão proposto passou por alguns percalços que impuseram limitações às metas propostas. Entre o Módulo 7 e o Módulo 8 as escolas estaduais entraram em greve e, com isso, os professores não puderam aplicar seus planos de aula. Como consequência, muito se perdeu em termos de reflexão não somente do próprio professor, mas também do grupo como um todo, sobre a apropriação [e aplicação] dos conteúdos abordados na formação.

A partir das observações feitas, das discussões nos encontros e da análise da apresentação dos planos de aula no Módulo 8, da análise dos planos de aula enviados por e-mail, e da avaliação feita pelos participantes, foi possível fazer alguns apontamentos pertinentes aos aspectos pedagógicos de uso de REA e dois deles são destacados aqui. Primeiro, o curso de extensão proposto teve êxito ao chamar a atenção dos professores quanto ao uso legal e ético de diferentes tecnologias digitais e dos conteúdos disponíveis da Internet. Os participantes se mostraram surpresos, por exemplo, em relação à busca e uso de conteúdo aberto no Google ou YouTube, tomando a consciência de que nem tudo que está na internet pode ser usado livremente. Em seus planos de aula, muitos usaram outros recursos abertos apresentados durante o projeto de extensão a exemplo de Canva, Toondoo, Flickr e Pixabay. Entretanto, ao pedir para os alunos executarem alguma tarefa que exigiria o uso de recursos tecnológicos, alguns professores não deixaram claro, no plano de aula, se esses alunos foram também orientados quanto à necessidade de usar recursos abertos. Outros, já indicaram qual recurso aberto os alunos deveriam usar para desenvolver uma determinada tarefa prevista no plano de aulas.

\footnotetext{
12 Disponível em: www.elo.pro.br

${ }^{13}$ Disponível em: http://www.educadores.diaadia.pr.gov.br/modules/conteudo/conteudo.php?conteudo=1669
} 
Entre as dificuldades encontradas e relatadas pelos professores está a falta de recursos tecnológicos disponíveis nas escolas, o que levou muito do uso dos REA presentes no plano de aula a ser feito com o objetivo de facilitar a vida do professor (por exemplo, a produção de slides para a apresentação do conteúdo), e não, necessariamente, a serem usados pelos alunos em sala de aula ou em laboratórios de Informática das escolas.

Segundo, além da dificuldade encontrada por alguns professores com a produção do plano de aula em si, a transposição das aprendizagens essenciais da BNCC (2017) para os planos de aula se apresentou também como uma dificuldade; apenas dois professores buscaram trabalhar com gêneros em seus planos: entrevista e propaganda. Alguns professores fizeram seus planos de aula com o foco em algum aspecto gramatical de forma descontextualizada e não significativa para os alunos, contrariando os pressupostos da BNCC. Sugestões foram dadas para que esses planos fossem repensados e refeitos.

Esses dois pontos destacados aqui já oferecem elementos para a elaboração de novos projetos de extensão e, assim, para a contínua contribuição para a formação dos professores de inglês do Ensino Fundamental II e Médio das escolas estaduais de Foz do Iguaçu.

\section{CONSIDERAÇÕES FINAIS}

O curso aqui apresentado teve como intuito de levar os professores de língua inglesa para uma reflexão acerca de sua práxis diária e da inclusão tecnologias digitais, em especial de recursos educacionais abertos, em suas práticas pedagógicas, e atendeu a um grupo de 20 professores da rede pública estadual de ensino da cidade de Foz do Iguaçu, PR, Brasil, dos quais 13 concluíram a formação (mais de setenta e cinco por cento de frequência e ter entregue a atividade final solicitada).

Por meio do contexto apontado pela pesquisa de Mello (2018), evidenciou-se a necessidade de suprir algumas das necessidades dos professores. Assim, a formação continuada seria uma maneira de incentivar e fomentar o uso das TDIC em sala de aula, bem como direcionar para os professores os tipos de ferramentas que podem ser utilizadas e quais estratégias podem ser adotadas em decorrência dos diversos resultados das aplicações de propostas pedagógicas advindas da formação.

Concebendo o professor da escola pública como produtor de conhecimento, enquanto professor-pesquisador, capaz de relatar suas reflexões a partir da sua vivência científica por meio da proposta de ferramentas e possíveis atividades advindas do curso, possibilita-se um norte inicial, incentivo e possibilidades de ensino.

Oferecida como curso de extensão, a formação continuada desses professores ora relatada teve como ponto de partida os trabalhos e discussões no Grupo de Pesquisa sobre Tecnologias no uso, no ensino e na aprendizagem de línguas estrangeiras, e teve como grande objetivo aproximar universidade e escola, criando um ambiente de discussões relevantes e enriquecedoras.

Destaca-se como resultado desse evento a possibilidade de criação de uma comunidade de professores que promovem a disponibilização solidária de planos de ensino online. Entretanto, há a necessidade de fomentar, continuamente, esse sentimento de comunidade, seja por meio das redes 
sociais ou pela promoção de novas formações.

\section{REFERÊNCIAS BIBLIOGRÁFICAS}

BRASIL. Ministério da Educação. Secretaria da Educação Básica. Base nacional comum curricular. Brasília, DF, 2017. Disponível em: < http://download.basenacionalcomum.mec.gov.br/>. Acesso em: out. 2019.

BRASIL. Lei 9.610: Lei dos Direitos Autorais. LDA. Disponível em http://www.planalto.gov.br/Ccivil_03/Leis/L9610.htm. Acesso em 20/03/2020.

DAVIES, G.; OTTO, S. E. K.; RÜSCHOFF, B. Historical Perspective on CALL. In: Contemporary Computer-Assisted Language Learning. London: Bloomsbury, 2013. p. 19-38.

EDUCAÇÃO ABERTA. Recursos Educacionais Abertos (REA): Um caderno para professores. Campinas, 2013. Disponível em: <http://educacaoaberta.org/cadernorea>. Acesso em: 23 set. 2018.

ESHET-ALKALAI, Y. Digital Literacy: a conceptual framework for survival skills in the digital era. Journal of Educational Multimedia and Hypermedia, v. 13, n. 1, 2004. p. 93-106.

FILATRO, A.; CAVALCANTI, C. C. Metodologias inov-ativas na educação presencial, a distância e corporativa. 1ạ ed. São Paulo: Saraiva Educação, 2018.

GONSALES, P.; SEBRIAM, D.; MARKUN, P. Como implementar uma política de Educação Aberta e Recursos Educacionais Aberto (REA): guia prático para gestores. São Paulo: Cereja Editora, 2017.

HEALEY, D. Language Learning and Technology: past, present and future. In: The Routledge Handbook of Language Learning and Technology. New York: Routledge, 2016. p. 9-23.

HOUSE, J. Teaching Oral skills in English as a Lingua Franca. In: ALSAGOFF, Lubna. et al. Principles and Practices for Teaching English as an International Language. New York: Taylor \& Francis Group, 2012, p. 186-205.

KRAMSCH, C. Context and Culture in Language Teaching. Oxford: Oxford University Press, 1993.

LINS, T. M.; BOSCARIOLI, C. A Tecnologia nas Licenciaturas em Letras Português/Inglês das Universidades Públicas Paranaenses: Uma Análise Documental. Revista Alameda. v. 7, n. 1, p. 111129. Disponível em: <http://e-revista.unioeste.br/index.php/alamedas/article/view/22492/14434> . Acesso em 30 maio 2020.

MALLMANN, E. M. JACQUES, J. S.; SONEGO, A. H. S.; TEIXEIRA, T. G.; TOEBE, I. C. D.; DOMINGUES, F. R. Potencial dos Recursos Educacionais Abertos para Integração das Tecnologias e Convergência entre as Modalidades na UFSM. Revista Eletrônica de Educação, v. 7, n. 2, 2013, p. 263-284. Disponível em:http://www.reveduc.ufscar.br/index.php/reveduc/article/view/742 . Acesso em 22 out. 2019.

MELLO, E. C. F. O uso de tecnologias nas aulas de língua inglesa no ensino fundamental II de Foz do Iguaçu/PR. 2018. 162 f. Dissertação (Mestrado em Ensino) - Universidade Estadual do Oeste do Paraná, Foz do Iguaçu, 2018. 
MELLO, E. C. F.; BOSCARIOLI, C. Recursos educacionais abertos nas aulas de língua inglesa: Criação de atividades alinhadas à Base Nacional Comum Curricular. Revista Polyphonía, v. 30, n. 1, 2019, p. 120-132. Disponível em: https://doi.org/10.5216/rp.v30i1.60195 . Acesso 12 maio 2020.

PINTO, J. V. Um estudo sobre literacia digital e possibilidades de aplicabilidade em contextos formativos de professores. 264 f. Dissertação (Mestrado em Ensino). Universidade Estadual do Oeste do Paraná, Foz do Iguaçu. 2019.

PINTO, J. V.; CAPPELLI, C.; BOSCARIOLI, C. Uma Proposta de Formação Continuada em Literacia Digital no Contexto Pedagógico. In: Anais do IV Congresso Brasileiro de Ensino e Processos Formativos (CBEPF 2019). Disponível em: <http://www.cbepf.com.br/ae/cbepf2019/anais/index.php?t=TC2019232299760\#> . Acesso em 30 maio 2020.

RAJAGOPALAN, K. Por uma linguística crítica: Linguagem, Identidade e a Questão Ética. São Paulo: Parábola Editorial, 2003.

REVUZ, C. A língua estrangeira entre o desejo de um outro lugar e o risco do exílio. In: Lingua(gem) e identidade. São Paulo: Mercado de Letras, 1998.

ROSSINI, C.; ABDO, A. Recursos Educacionais Abertos: Perguntas frequentes. 2011. Disponível em: http://aberta.org.br/faq/. Acesso em 12 mai. 2020.

SILVA, D. A. A formação continuada em tecnologias digitais ofertada no Paraná sob a ótica de professores da rede estadual de Foz do Iguaçu. 2018. 137 f. Dissertação (Mestrado em Ensino) Universidade Estadual do Oeste do Paraná, Foz do Iguaçu, 2018.

THOMAS, M.; REINDERS, H.; WARSCHAUER, M. Contemporary computer-assisted language learning: the role of digital media and incremental change. In: Contemporary Computer-Assisted Language Learning. London: Bloomsbury, 2013. p. 1-12.

UNESCO. Guidelines for Open Educational Resources (OER) in Higher Education. Vancouver: Columbia, 2011. Disponível em: http://unesdoc.unesco.org/images/0021/002136/213605E.pdf . Acesso em: 22 out. 2019.

WARSCHAUER, M. Computer-Assisted Language Learning: An Introduction. In: Multimedia Language Teaching. Tokyo: Logos International, 1996. p. 3-20. Disponível em: <http://www.ict4lt.org/en/warschauer.htm>. Acesso em: out. 2019.

WILEY, D. (2014). The Access Compromise and the 5th R. Iterating Toward Openness. Recuperado de http://opencontent.org/blog/archives/3221. Acesso em: 17 jul. 2020.

Recebido em 31/05/2020

Aceito em 21/07/2020

(c) (i) (5) (2) 